\title{
Design guidelines for avoiding thermo-acoustic oscillations in Helium piping systems
}

\author{
Prabhat Kumar Gupta ${ }^{\mathrm{a},{ }^{,}, 1}$, Roger Rabehl ${ }^{\mathrm{b}}$ \\ ${ }^{a}$ Cryo-Engineering and Cryo-Module Development Section, Raja Ramanna Centre for \\ Advanced Technology (RRCAT), Indore (MP), India \\ ${ }^{\mathrm{b}}$ Test and Instrumentation Department, Technical Division, Fermi National Accelerator \\ Laboratory, Batavia, IL, USA
}

\begin{abstract}
Thermo-acoustic oscillations are a commonly observed phenomenon in helium cryogenic systems, especially in tubes connecting hot and cold areas. The open ends of these tubes are connected to the lower temperature (typically at $4.5 \mathrm{~K}$ ), and the closed ends of these tubes are connected to the high temperature $(300 \mathrm{~K})$. Cryogenic instrumentation installations provide ideal conditions for these oscillations to occur due to the steep temperature gradient along the tubing. These oscillations create errors in measurements as well as an undesirable heat load to the system. The work presented here develops engineering guidelines to design oscillation-free helium piping. This work also studies the effect of different piping inserts and shows how the proper geometrical combinations have to be chosen to avoid thermo-acoustic oscillations. The effect of an $80 \mathrm{~K}$ intercept is also studied and shows that thermo-oscillations can be dampened by placing the intercept at an appropriate location. The design of helium piping based on the present work is also verified with the experimental results available in open literature.
\end{abstract}

Keywords: Helium Piping, Thermo-acoustic Oscillations, Cryogenic Systems

*Corresponding author:Prabhat Kumar Gupta

Email addresses: Prabhat Kumar Gupta (prabhat@rrcat.gov.in),Roger

Rabehl(rabehl@fnal.gov)

${ }^{1}$ Work reported in this article was conducted during the stay of the first author at Fermilab as a Guest Cryogenic Engineer. 


\section{Introduction}

Cryogenic systems are very susceptible to thermal-oscillation instabilities. When a gas column in a long cylindrical tube is subjected to strong temperature gradients, it may spontaneously oscillate with large amplitudes. These thermo-oscillations are generally called Taconis oscillations. These Taconis oscillations are most problematic in helium cryogenic systems where one end of a tube is at liquid helium temperature and other end of the tube is at ambient temperature. These oscillations can result in an enormous heat flux at the cold end, up to 1000 times greater than the tube conduction itself [1]. Rott [2] successfully generated the stability curves for oscillations in helium systems, predicting the oscillating and non-oscillating zones. Rott discovered that there are two branches of the curve, a lower branch and an upper branch. Both of these branches join at a single point below which there are no excited oscillations. He also concluded that the upper branch of the stability curve does not have any practical significance because of the excessively high temperature ratios required. Today, these curves serve as a primarily design criteria to identify or predict where oscillations will occur. As a reminder of Rott's analysis, a stability curve for helium gas developed by him is reproduced in this paper. Figure 1 shows the stability diagram developed by Rott [2]. The phase diagram generated by Rott has also been verified experimentally by many researchers [1, 3]. Experimental verification of Rott's stability curve done independently by Fuerst is reproduced here in Figure 2 [1]. Another experimental work for liquid helium system is reported by Youfan and Timmerhaus [4] and reproduced in Figure 3. They all concluded that cryogenic oscillations can be predicted with reasonable accuracy with the help of the Rott stability curves.

The stability curve generated for helium gas indicates that thermal oscillations can be avoided if proper attention is paid during the design stage. Certain combinations of tube length and tube inner diameter will result in an oscillation-free system. Moreover, any existing thermal oscillations in the system can be dampened by altering the operating temperature ratio between the hot and cold ends by providing an $80 \mathrm{~K}$ intercept. The location of this intercept must be chosen carefully.

Different experimental and analytical work, as reproduced in this paper, has been reported for helium cryogenics in open literature. But to the best knowledge of the 
present authors, there are no clear, simple, and ready to use design guidelines existing in literature to design oscillation-free helium piping. Furthermore, it is also not straightforward to determine acceptable length-diameter combinations based on the present available literature. Therefore, the present work is aimed at describing engineering design guidelines for helium piping systems to avoid thermal oscillations. Stabilitylimited length and inner diameter combinations have been generated using the Rott mathematical model and verified with available experimental results in tabular form. The present work is also extended to formulate the design guidelines in the presence of tube inserts, describing how to choose acceptable length-diameter combinations to result in an oscillation-free system. The appropriate location of an $80 \mathrm{~K}$ intercept to dampen oscillations in a tube with one end at $300 \mathrm{~K}$ and the other end at $4.5 \mathrm{~K}$ is also analyzed as a function of tube length and inner diameter.

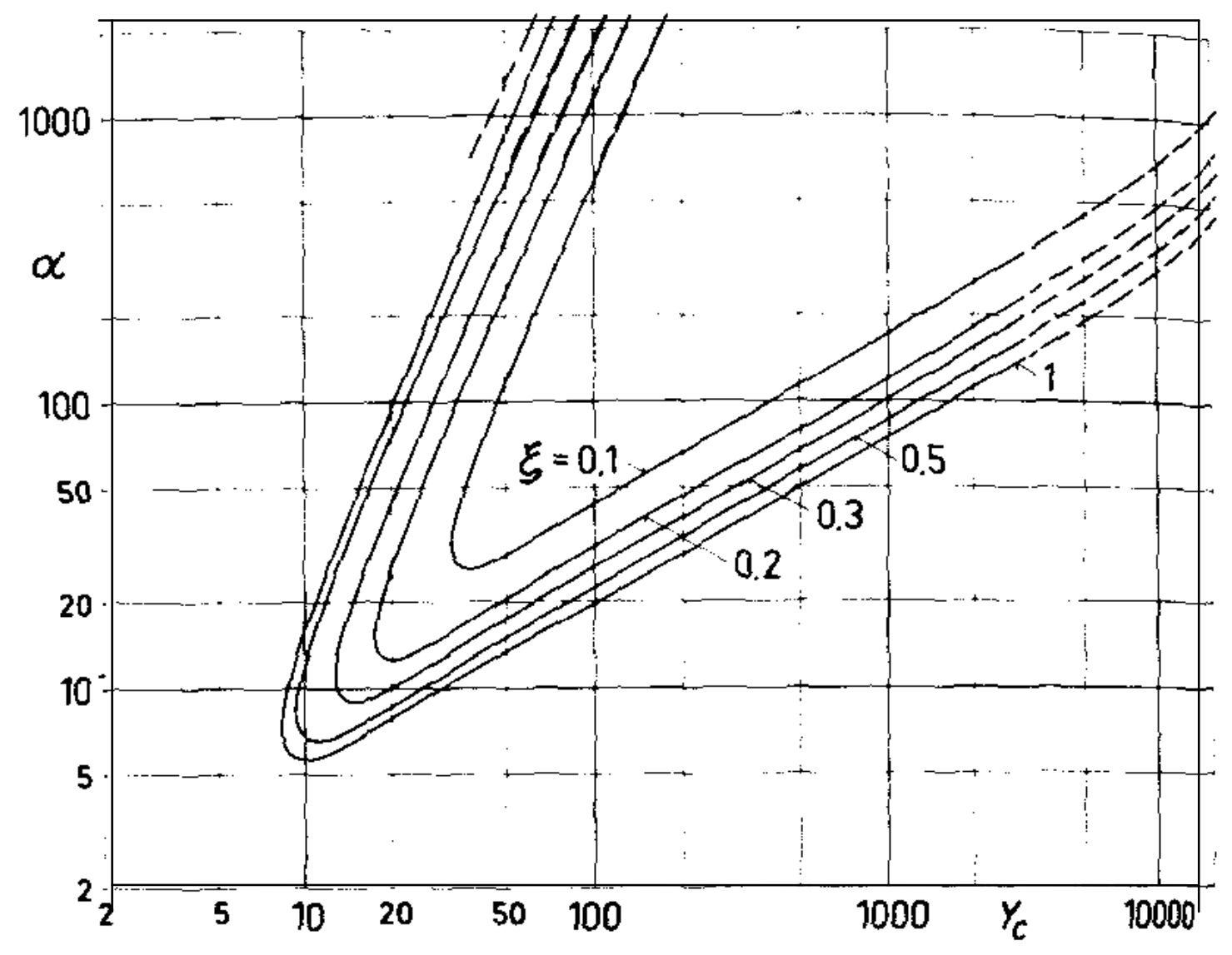


Figure 1. Stability curves for helium, the hot-to-cold temperature ratio $\alpha=\frac{T_{H}}{T_{C}}$ versus $Y_{c}=\frac{d_{o}}{2}\left[\frac{a_{c}}{l v_{c}}\right]^{\frac{1}{2}}$ for given values of $\xi=\frac{L-l}{l}$. Figure 3 of reference 2 is reproduced here with permission as a reminder.

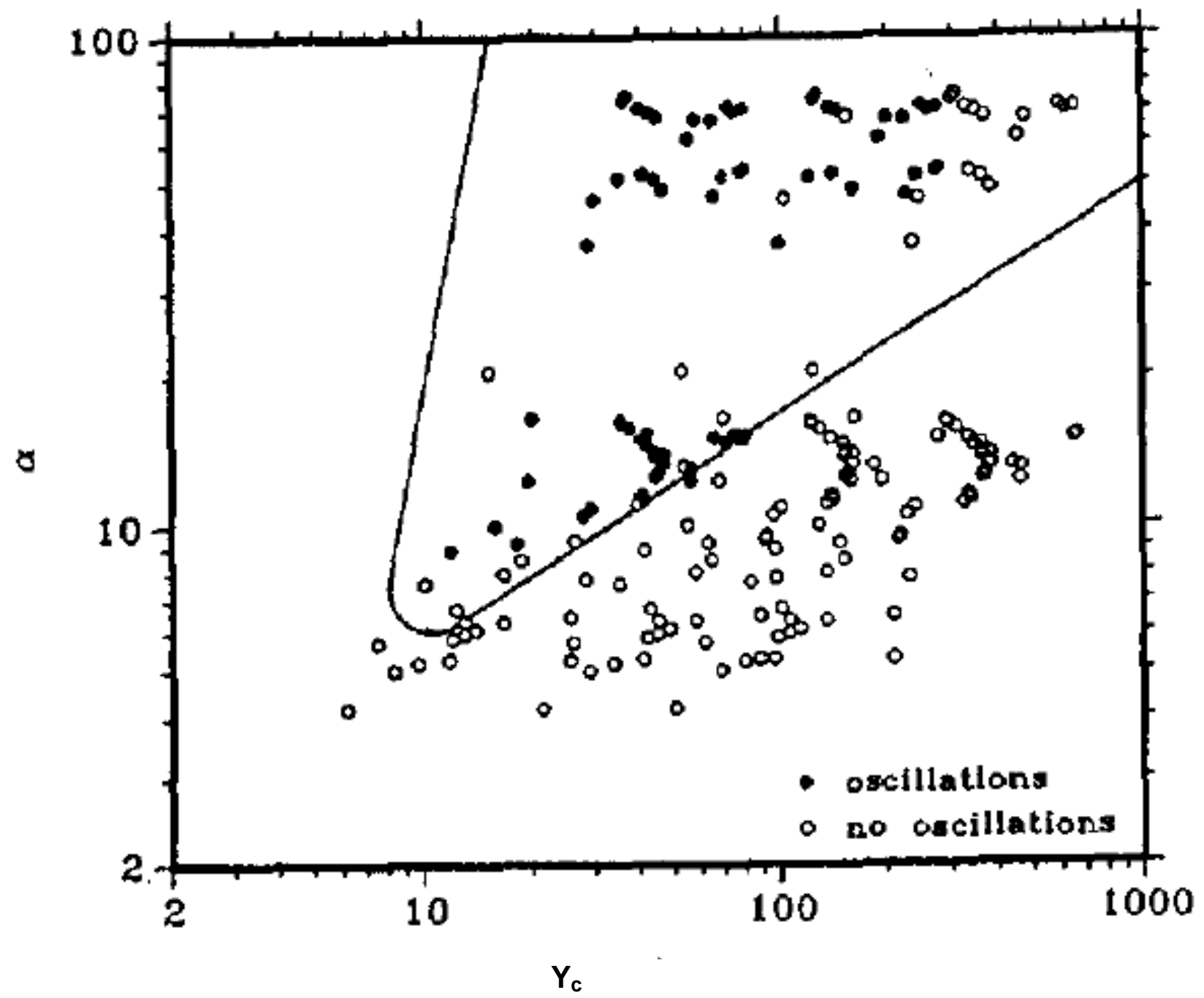

Figure 2. Experimental verification of stability curve for $\xi=\frac{L-l}{l}=1[1]$. 


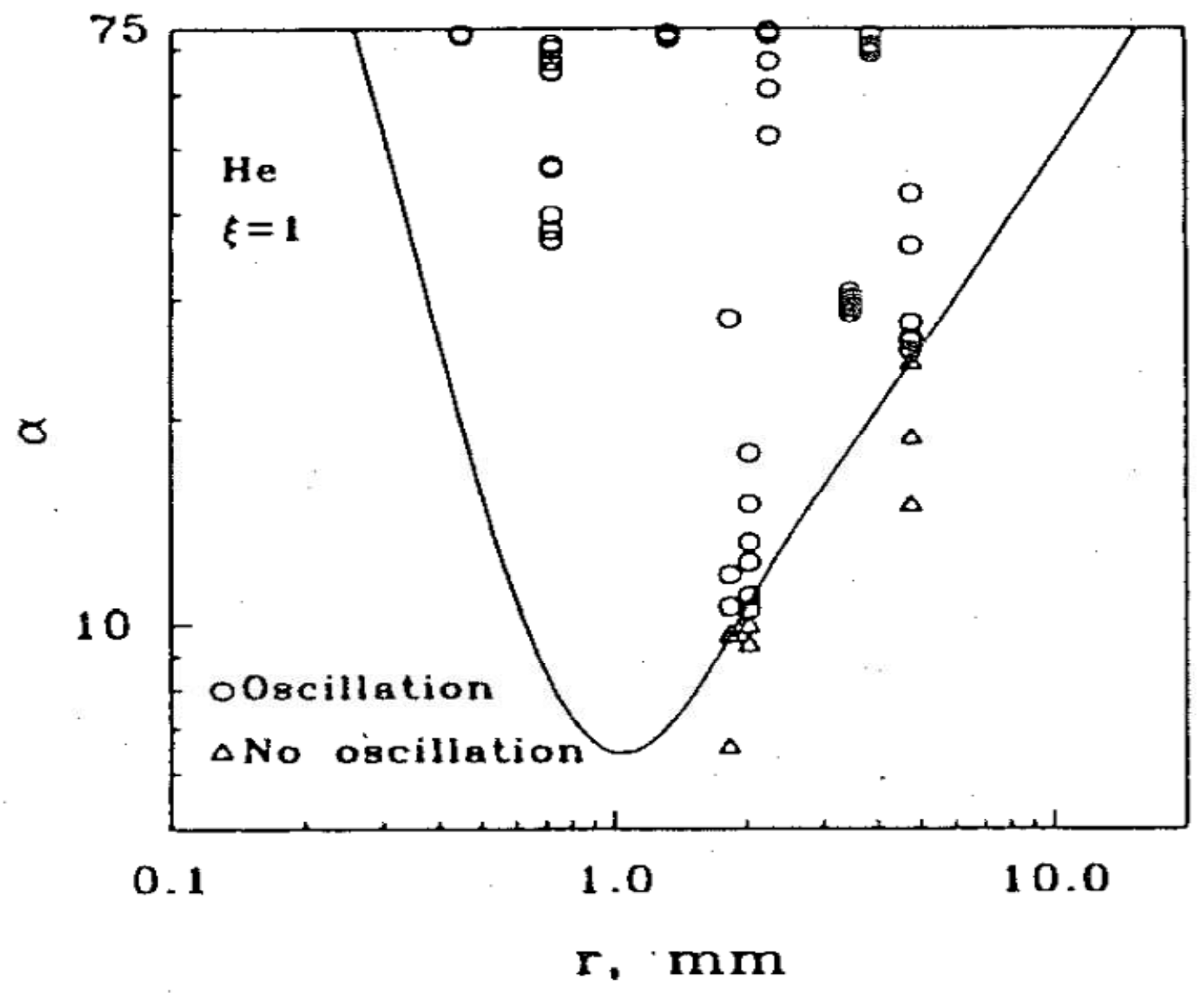

Figure 3. Experimental verification of stability curve, the hot-to-cold temperature ratio $\alpha=\frac{T_{H}}{T_{C}}$ versus radius $\mathrm{r}$ for $\xi=\frac{L-l}{l}=1$ [4]. Reprinted with permission.

\section{Analysis}

Figure 4 shows a typical arrangement of helium piping with one end at $4.5 \mathrm{~K}$ and the other end at $300 \mathrm{~K}$. It is assumed that the tube is filled with helium gas at 1.3 bar absolute pressure corresponding to $4.5 \mathrm{~K}$ saturated temperature. The helium gas column confined in the tube is assumed to be oscillating. 


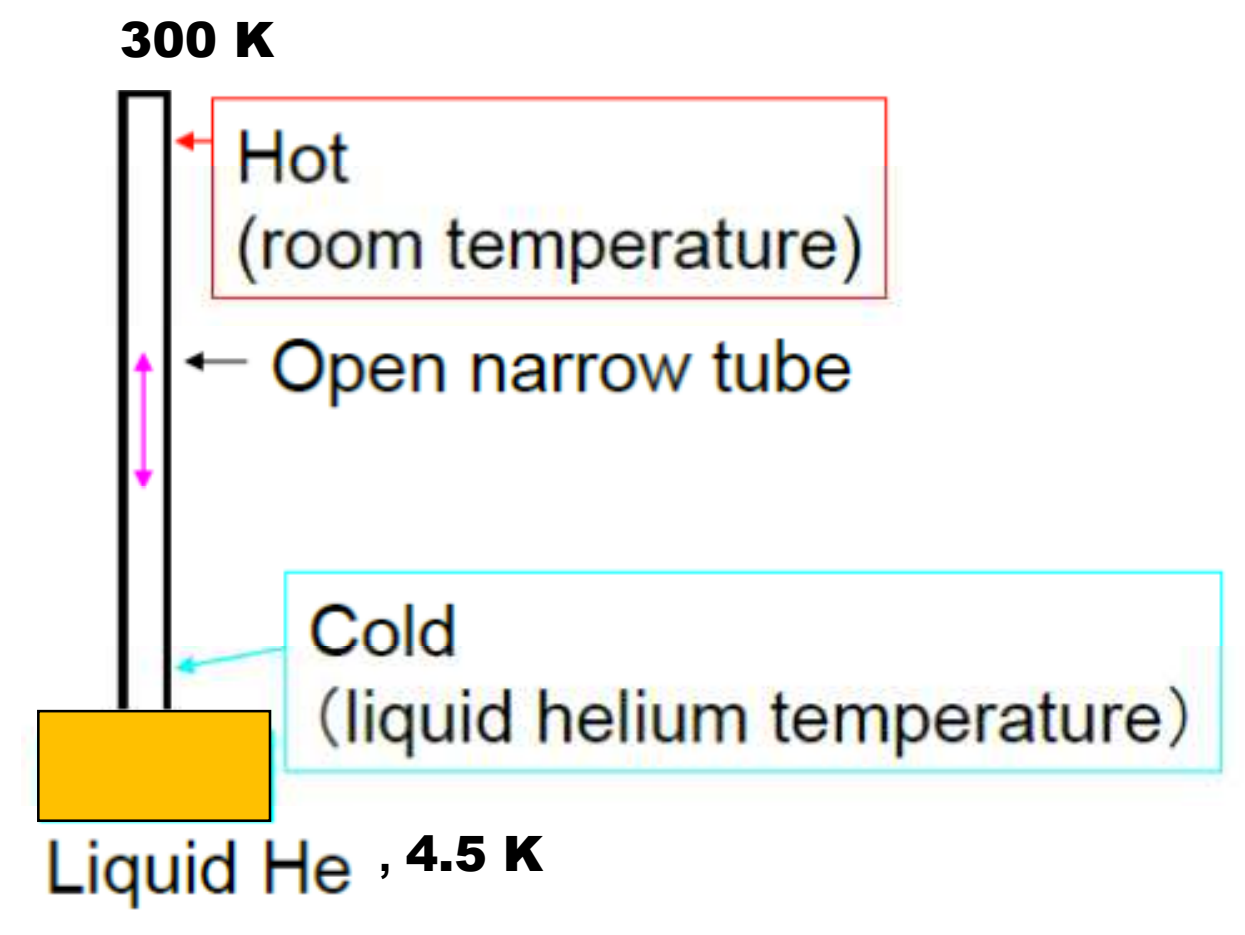

Figure 4. Typical example of a helium piping system.

According to Rott's theory, the optimum position of the temperature jump (temperature rise from cold end temperature to hot end temperature) for excited oscillations lies near the middle of the half-open tube and remains practically unaffected up to a hot-to-cold length ratio of $2: 1$. Therefore, the present analysis is based on the assumption that this temperature jump occurs at the center of the tube as shown in Figure 5. From a closer look at the Rott stability curves, it can also be said that assuming this temperature jump occurs at the center $(\xi=1)$ will always produce conservative design criteria for given temperature ratios. Figure 1 gives the maximum value of Yc (outer most curve) for $\xi$ $=1$ and for given value of $\alpha$. Maximum value of $Y_{\mathrm{c}}$ will always result in minimum critical diameter of tube for a given length for oscillation free tube sizing.

To illustrate the position of this temperature jump mathematically, it can be seen from Figure 5 that at $x=0$, the tube is open and the temperature can rise to the hot end temperature over a very small portion of the tube $(\Delta x<<1)$ near its center. Therefore it can be assumed that the helium gas will have a constant temperature $T_{L}$ between $x=0$ 
and $x=I$. At $x=L$, the tube will be closed and it will be at constant temperature $T_{H}$ between $x=1$ and $x=L$. The position of the temperature jump can be given mathematically as the ratio of hot end tube length to cold end tube length and can be expressed as

$\xi=\frac{L-l}{l}$

In the present analysis, a constant $\xi=1$ is used by assuming the temperature jump occurs at the center.

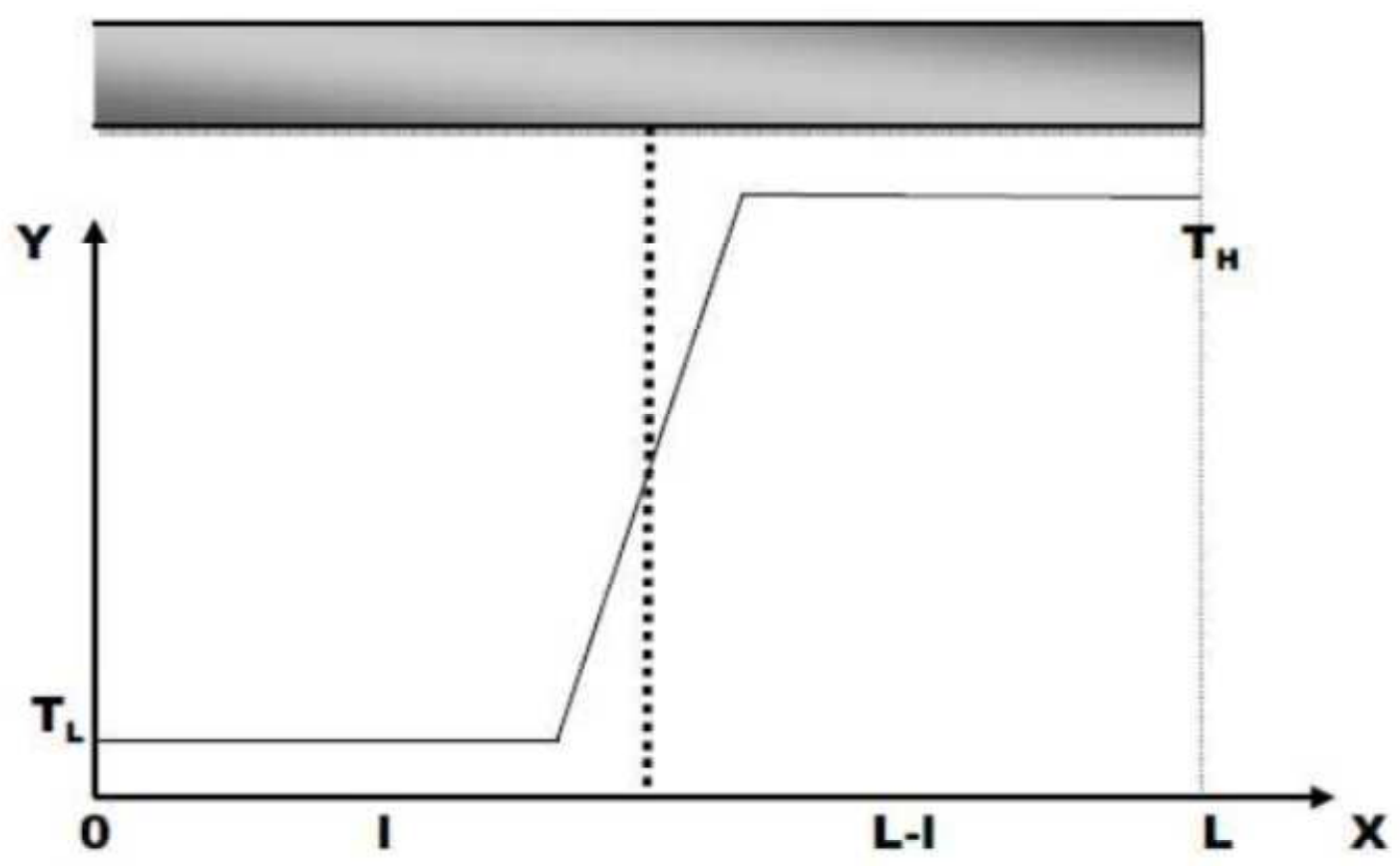

Figure 5. Illustration of temperature distribution along the tube.

The goal of this document is to develop an analysis and useful guidelines which can be directly applied to the practical purpose of designing oscillation-free helium piping systems or damping out oscillations in existing helium piping systems. The lower branch of the Rott stability curve is used for the analysis, and this stability curve is generated using the Equation 18 from Ref. [2]

$Y_{c}=\frac{2 D \alpha^{1+\beta}}{\left(1+\xi^{-1}+\lambda_{c}^{2} \xi\right)}$ 
where $\alpha$ is the hot-to-cold temperature ratio expressed as

$\alpha=\frac{T_{H}}{T_{L}}$

The value of $\lambda_{c}$ in Eq. (2) is given by

$\lambda_{c}=\frac{\omega l}{a_{c}}$

where $\omega$ is the angular frequency, $a_{c}$ is the sound speed in the gas at cold end, and $I$ is the tube cold length. The value $\lambda_{c}$ is varied from 0.8 to 1.4 for $\xi=1$ and can be approximated to 1 for calculation.

According to Rott's analysis $\mathrm{D}$ is a constant and the exponent $\beta$ is strongly dependent on the intermolecular force field and can be set to an empirical constant for helium over the temperature range of 300-4.5 K. These constants values used in Eq.(2) are $D=1.19$ [2], $\beta=0.647$ [2] for helium, and $\xi=1.0$ as discussed earlier. The stability curve generated from Eq. (2) for $\xi=1.0$ is shown in Figure 6.

The stability limit $Y_{c}$ calculated from Eq. (2) is in excellent agreement with numerical values plotted in Figure 6 of Ref. [2]. Therefore Eq. (2) can be directly used to get the stability limit for different temperature ratios $\alpha$.

The physical phenomena underlying the driving potentials of thermo-acoustic oscillations in tubes depend on the viscous action of the fluid on the tube surfaces. Thermo-physical properties of the fluid and geometric parameters of the tube, such as length and inner diameter, play a crucial role propagating or damping these oscillations. To represent this physical phenomena Rott has introduced a parameter $Y_{c}$, ratio of tube inner radius to Stokes boundary layer thickness. This parameter controls the amplitude of a Taconis oscillation and is given by 
$Y_{c}=\frac{d_{0}}{2}\left[\frac{a_{c}}{l v_{c}}\right]^{\frac{1}{2}}$

where $d_{o}$ is the tube inner diameter and $\vartheta_{c}$ is the kinematic viscosity of the fluid.

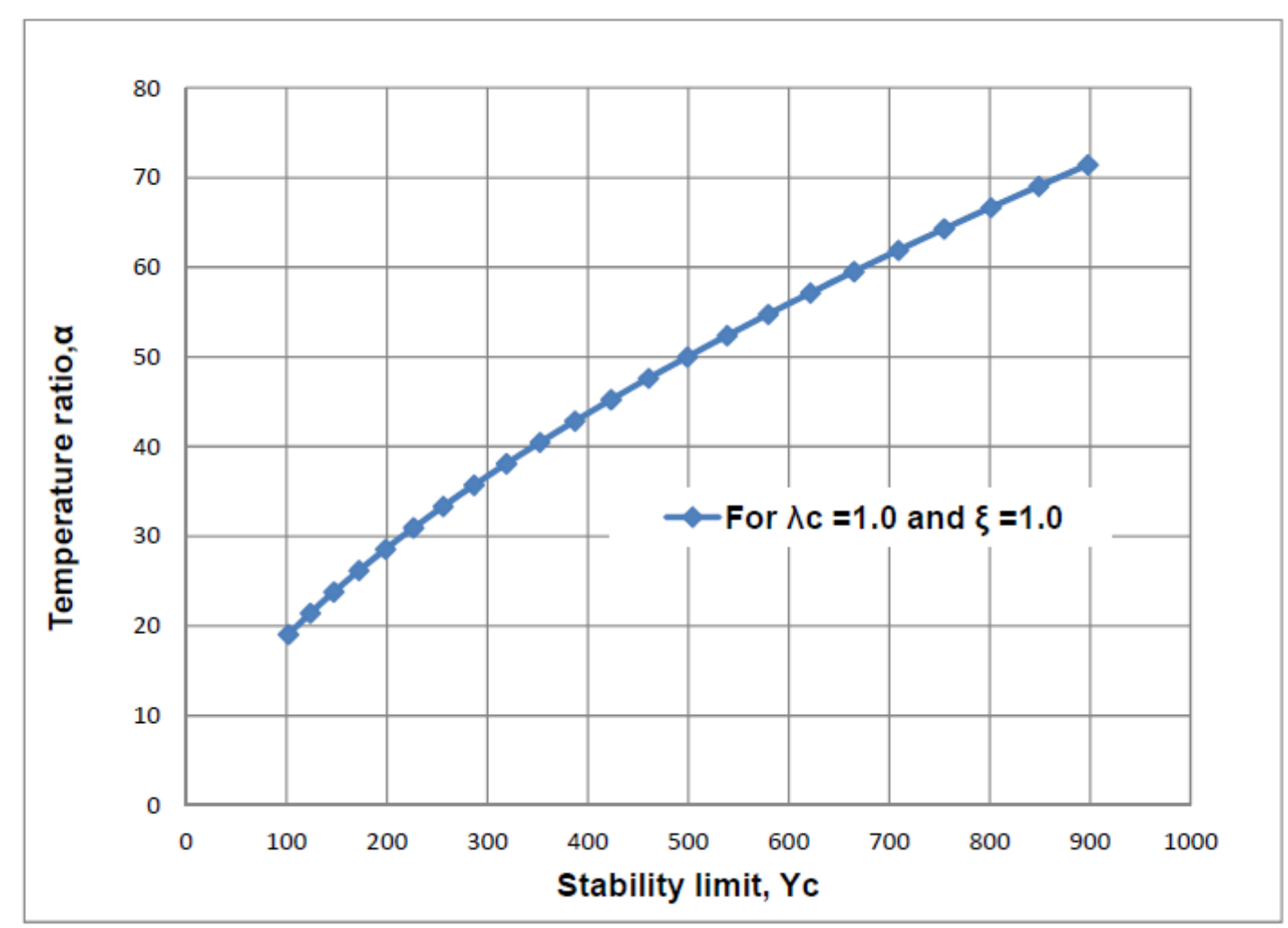

Figure 6. Lower stability curve from Eq.(2).

The dimensionless parameter $Y_{c}$ for stability given in Eq.(2) is a numerical solution derived in reference 2 in terms of $Y_{c}$ for the same physical phenomena and can be directly compared to Eq. (5) in order to set the critical limit of tube inner diameter for a given tube length and temperature ratio. Therefore

$\frac{d_{o}}{2}\left[\frac{a_{c}}{l v_{c}}\right]^{\frac{1}{2}}=\frac{2 D \alpha^{1+\beta}}{\left(1+\xi^{-1}+\lambda_{c}^{2} \xi\right)}$

$d_{o, \text { critical }}=\frac{4 D \alpha^{1+\beta}}{\left(1+\xi^{-1}+\lambda_{C}^{2} \xi\right)}\left[\frac{l v_{C}}{a_{C}}\right]^{\frac{1}{2}}$ 
The critical tube inner diameter given by Eq.(7) is an important parameter. Its practical significance and how it is useful in the piping design will be discussed in the upcoming section of this paper.

The present analysis also studied the effect of inserts in the tube. If the insert diameter is $d_{i}$, Eq. (7) can be modified as follows

$d_{o, \text { critical }}=\frac{4 D \alpha^{1+\beta}}{\left(1+\xi^{-1}+\lambda_{c}^{2} \xi\right)(1-\chi)}\left[\frac{l v_{c}}{a_{c}}\right]^{\frac{1}{2}}$

where $x=\frac{d_{i}}{d_{0}}$.

\section{Results and Discussion}

Based on the analysis presented in the above section, occurrence of thermo-acoustic oscillations for different tube length-diameter combinations can be mapped. This mapping can be directly applied by the designer for choosing a tube length-diameter combination so that the system will be oscillation-free. Figure 7 shows such a mapping diagram for different length-diameter combinations of practical interest.

Figure 7 displays the results for two cases. In the first case, one end of the tube is at $300 \mathrm{~K}$ and the other end is at liquid helium temperature $(\sim 4.5 \mathrm{~K})$. In the second case, one end of the tube is at $80 \mathrm{~K}$ and the other end is at liquid helium temperature ( 4.5 K). This figure shows two zones, oscillating and non-oscillating, for certain length-diameter combinations of the tube. One can quickly find from Figure 7 which length-diameter combinations will fall in the oscillating zone. For example, if one selects a $1 \mathrm{~m}$ length of instrumentation tubing to be connected between $300 \mathrm{~K}$ and $4.5 \mathrm{~K}$, then a tube inner diameter greater than $28 \mathrm{~mm}$ is required to ensure the helium piping will be oscillationfree. 


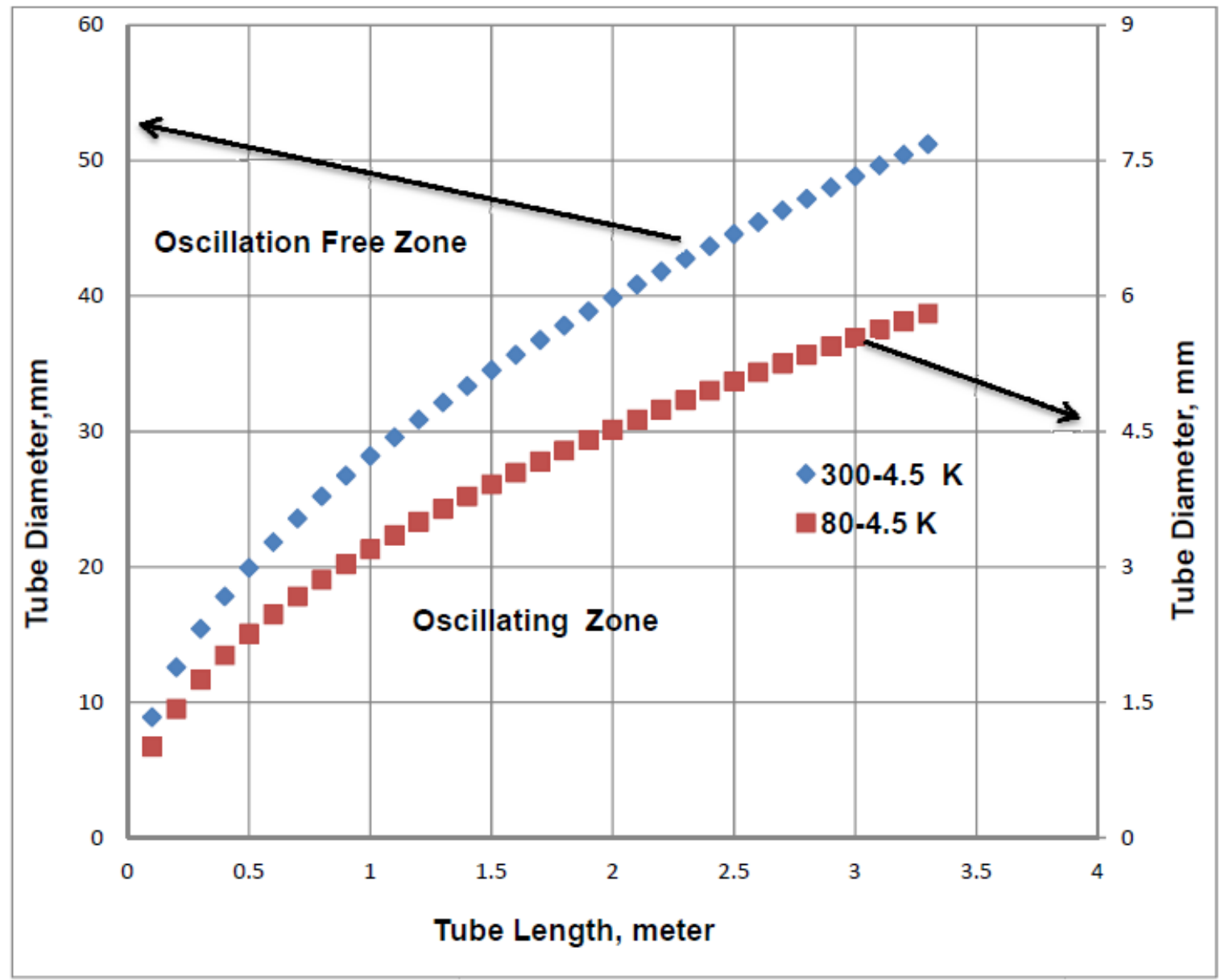

Figure 7. Thermo-acoustic oscillation mapping for different length-diameter combinations.

In cryogenic instrumentation piping, different kinds of inserts are used which reduce the effective volume inside the piping. Examples of common inserts are copper wires and nylon fish lines. Usage of inserts should be considered during piping design. Figure 8 maps the oscillating and non-oscillating zones for different length-diameter combinations when tube inserts are used. It shows that the combination of tube length and tube inner diameter should be selected based on what percentage of the tube inner diameter is occupied by inserts. For example, if $50 \%$ of the tube inner diameter ( $25 \%$ of the gas space cross-section in the tube) is occupied by inserts, one must select a tube inner diameter greater than $50 \mathrm{~mm}$ to ensure that a $1 \mathrm{~m}$ long tube will be oscillationfree. If inserts occupy $80 \%$ of the tube inner diameter $(64 \%$ of the gas space cross- 
section in the tube), one must select a tube inner diameter greater than $140 \mathrm{~mm}$ to ensure that the same $1 \mathrm{~m}$ long tube will be oscillation-free.

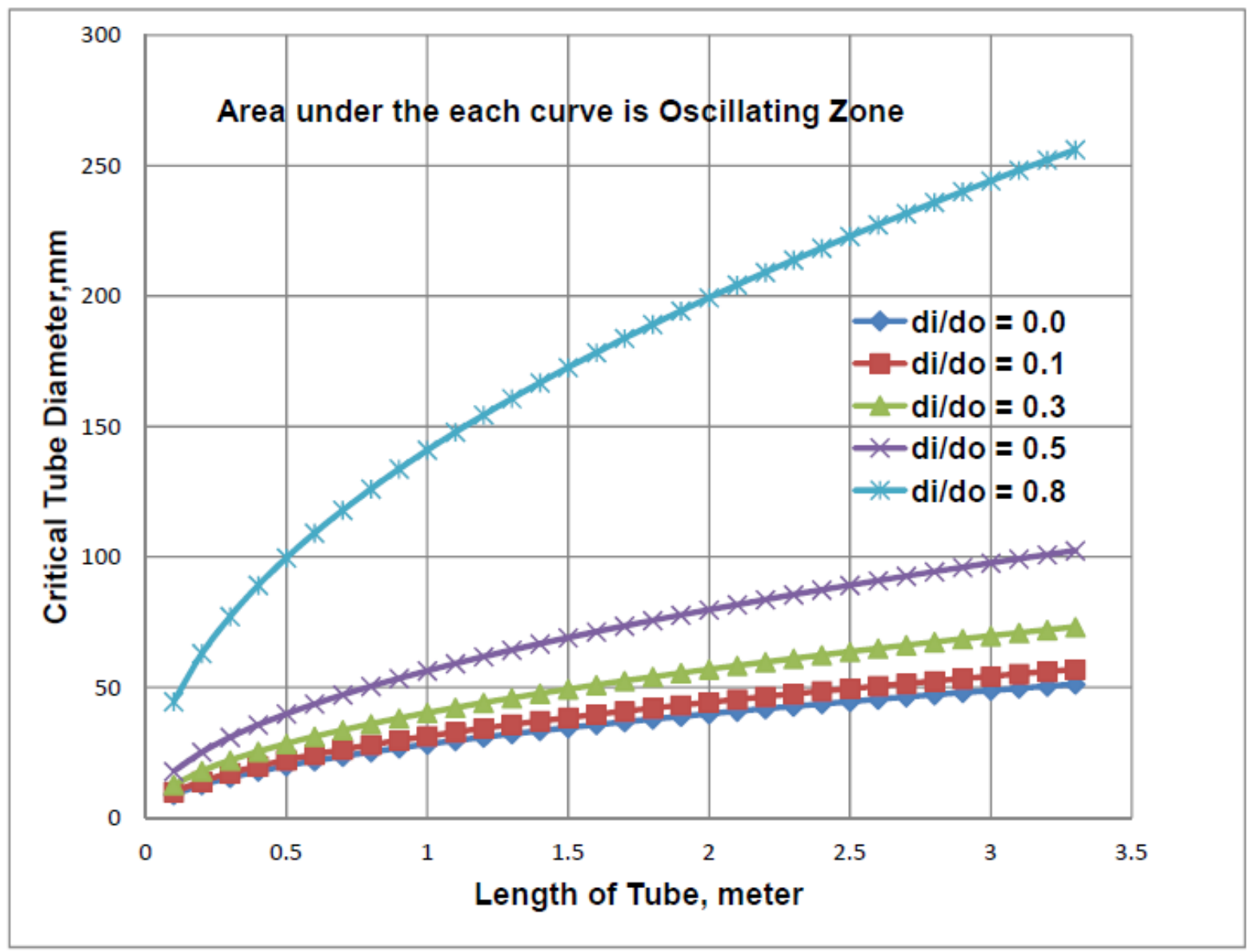

Figure 8. Length-diameter combinations in the presence of inserts for the temperature boundary conditions of $300 \mathrm{~K}$ and $4.5 \mathrm{~K}$.

Similarly, Figure 9 presents the selection criteria for a tube of which one end is $80 \mathrm{~K}$ and another end is maintained at $4.5 \mathrm{~K}$. It could be noticed from Figure 9 that tube diameter could be reduced significantly for the temperature boundary of $80 \mathrm{~K}-4.5 \mathrm{~K}$.

Many cryogenic systems use the $80 \mathrm{~K}$ intercept to dampen the thermo-acoustic oscillations. These intercepts typically are the $80 \mathrm{~K}$ heat sink tied to a tube. The analysis also studied the most appropriate location of an $80 \mathrm{~K}$ intercept to dampen the thermoacoustic oscillations in the tube without inserts. It is assumed the warm end is at $300 \mathrm{~K}$ and the cold end is at $4.5 \mathrm{~K}$. For a given tubing length and inner diameter, the maximum 
distance from $4.5 \mathrm{~K}$ (cold end) to the $80 \mathrm{~K}$ intercept (and therefore the minimum distance from the $80 \mathrm{~K}$ intercept to $300 \mathrm{~K}$ ) for oscillation-free operation is calculated by the stability limit $Y_{c}=90.86$. This stability limit has been calculated from Equation 2 for the fixed temperature ratio $\alpha=17.77\left(\alpha=\frac{T_{H}}{T_{L}}=\frac{80}{4.5}\right)$. This stability limit is the limiting factor to determine the most appropriate location of an $80 \mathrm{~K}$ intercept between the hot end $(300 \mathrm{~K})$ and the cold end $(4.5 \mathrm{~K})$.

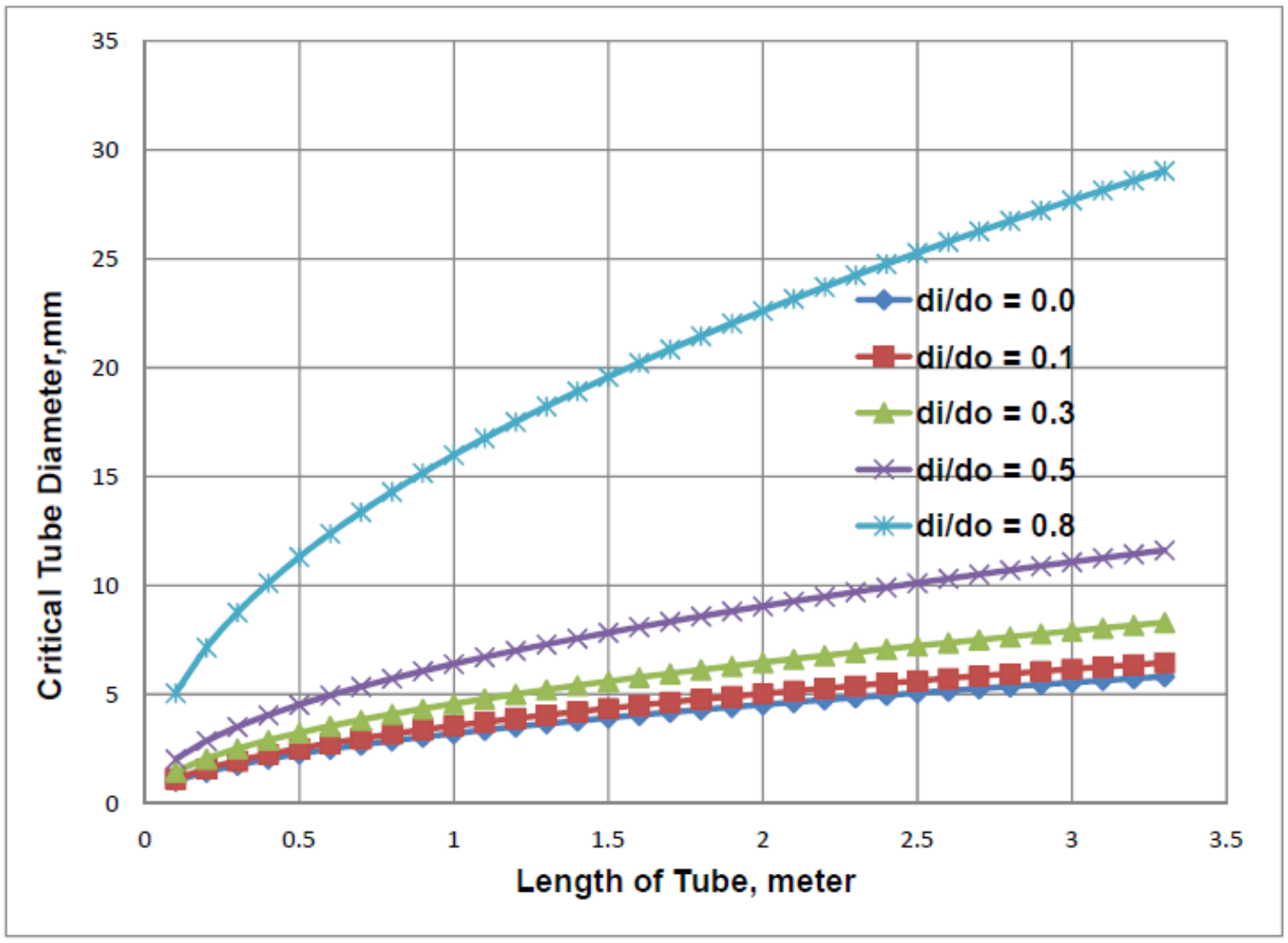

Figure 9. Length-diameter combinations in the presence of inserts for the temperature boundary conditions of $80 \mathrm{~K}$ and $4.5 \mathrm{~K}$.

Results of this analysis are shown in Figure 10. This analysis reveals some interesting facts. Figure 10 shows that there is a maximum distance for certain inner diameters of tubes. For a $5 \mathrm{~m}$ long tube, the maximum distance from the cold end $(4.5 \mathrm{~K})$ to the $80 \mathrm{~K}$ intercept is $2 \mathrm{~m}$ for a $4.57 \mathrm{~mm}$ inner diameter. If the tube inner diameter is $7.5 \mathrm{~mm}$ or greater, the $80 \mathrm{~K}$ intercept could be placed at any position for the same total length of 
tube. The results displayed in Figure 10 have been obtained by assuming that the tube is closed at different locations from cold end and is at $80 \mathrm{~K}$.

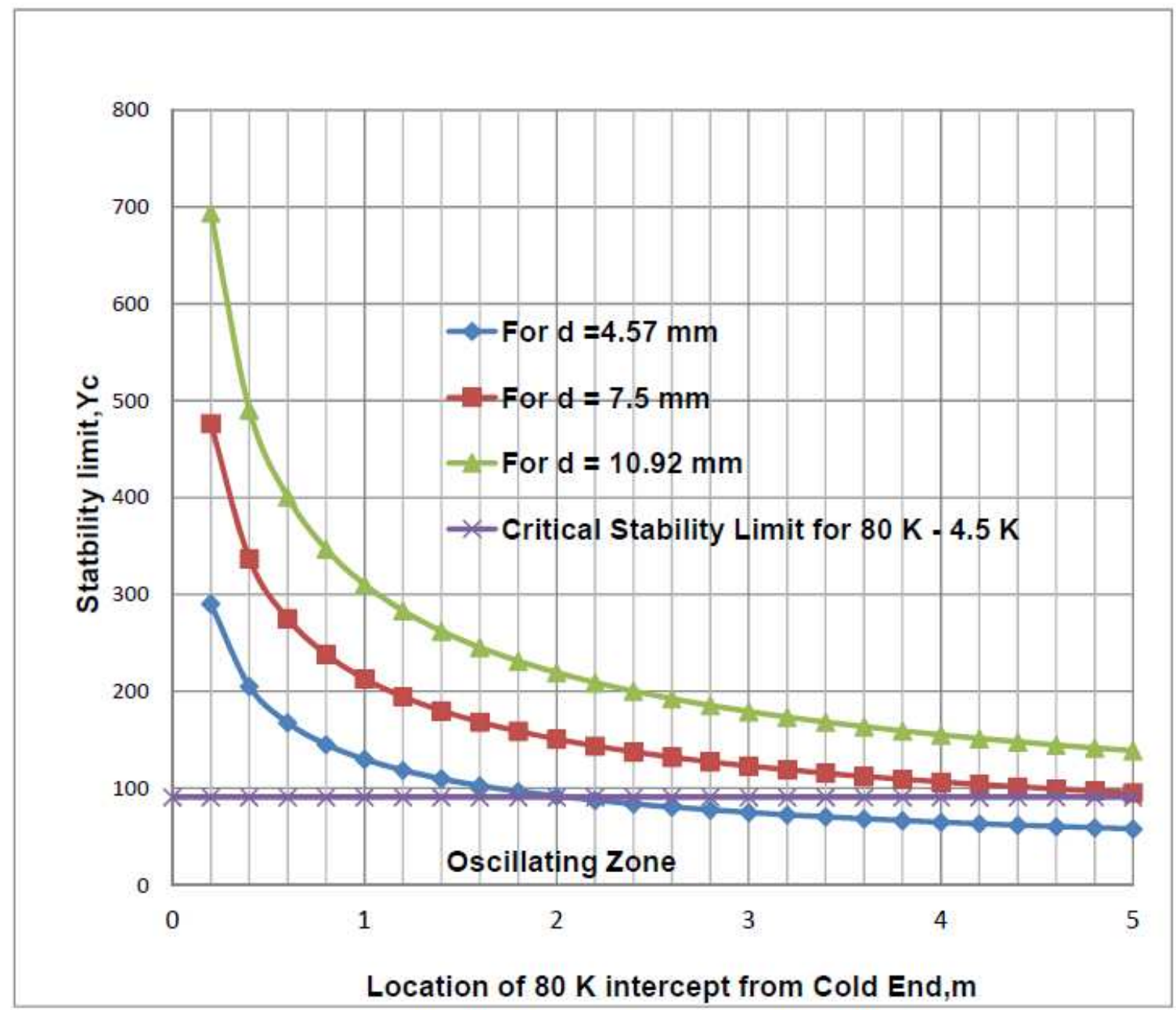

Figure 10. Stability-limited maximum distance of $80 \mathrm{~K}$ intercepts from the cold end to avoid thermo-acoustic oscillations.

\section{Experimental verification of present method}

Results obtained from the present method have been verified with the available results in open literature. The experimental results taken from elsewhere [1, 4] and graphs reproduced in the present work are used for the comparisons. The present method has been verified for the $300 \mathrm{~K}-4.5 \mathrm{~K}$ and $80 \mathrm{~K}-4.5 \mathrm{~K}$ temperature boundaries and also for $80 \mathrm{~K}$ intercepts locations. The tube sizes have been used as used in the experimental 
work done by Fuerst [1] for the comparisons. To verify these results, the stability limit $Y_{C}$ has been calculated from Eq.5 using geometrical parameters of tubes and helium properties. These data then have been compared with Figure 2 to determine whether they are locating in the oscillation zone or not for different values of $\alpha$. Similarly experimental values of Figure 3 have also been compared for different values of $\square$ for different tube diameters. These results have been tabulated in Table 1, Table 2 and Table 3. The simple method developed in the present work predicts well whether oscillations will occur and could be used for designing oscillation-free piping.

Table 1. Experimental verification of present helium piping design from the experimental results available in open literature [1, 4]: hot end at $300 \mathrm{~K}$, cold end at $4.5 \mathrm{~K}$, tube length: 1 meter

\begin{tabular}{|l|c|c|c|}
\hline Tube/pipe Sizes & $\begin{array}{l}\text { Thermo-acoustic } \\
\text { oscillation } \\
\text { occurrence, } \\
\text { experimental data } \\
\text { from Reference 1 }\end{array}$ & $\begin{array}{l}\text { Thermo-acoustic } \\
\text { oscillation } \\
\text { occurrence, } \\
\text { experimental data } \\
\text { from Reference 4 }\end{array}$ & $\begin{array}{c}\text { Predicted thermo- } \\
\text { acoustic oscillation } \\
\text { occurrence, data } \\
\text { from the present } \\
\text { analysis Figure 7 }\end{array}$ \\
\hline $\begin{array}{l}\text { OD } 3.18 \mathrm{~mm} \\
\text { ID } 1.40 \mathrm{~mm}\end{array}$ & Oscillations & Oscillations & Oscillations \\
\hline OD $6.35 \mathrm{~mm}$ & Oscillations & Oscillations & Oscillations \\
\hline ID $4.57 \mathrm{~mm}$ & Oscillations & Oscillations & Oscillations \\
\hline OD $12.70 \mathrm{~mm}$ \\
ID $10.92 \mathrm{~mm}$
\end{tabular}

Table 2. Experimental verification of present helium piping design from the experimental results available in open literature $[1,4]$ : hot end at $80 \mathrm{~K}$, cold end at $4.5 \mathrm{~K}$, tube length: 1 meter

\begin{tabular}{|c|c|c|c|c|}
\hline & Tube Sizes & $\begin{array}{l}\text { Thermo-acoustic } \\
\text { oscillation } \\
\text { occurrence, } \\
\text { experimental data } \\
\text { from Reference } 1\end{array}$ & $\begin{array}{l}\text { Thermo-acoustic } \\
\text { oscillation } \\
\text { occurrence, } \\
\text { experimental data } \\
\text { from Reference } 4\end{array}$ & $\begin{array}{l}\text { Predicted thermo- } \\
\text { acoustic oscillation } \\
\text { occurrence, data } \\
\text { from the present } \\
\text { analysis Figure } 7\end{array}$ \\
\hline $\begin{array}{l}\mathrm{OD} \\
\text { ID }\end{array}$ & $\begin{array}{l}3.18 \mathrm{~mm} \\
1.40 \mathrm{~mm}\end{array}$ & Oscillations & Oscillations & Oscillations \\
\hline $\begin{array}{l}\text { OD } \\
\text { ID }\end{array}$ & $\begin{array}{l}6.35 \mathrm{~mm} \\
4.57 \mathrm{~mm}\end{array}$ & No oscillations & No oscillations & No oscillations \\
\hline $\begin{array}{l}\mathrm{OD} \\
\text { ID }\end{array}$ & $\begin{array}{l}12.70 \mathrm{~mm} \\
10.92 \mathrm{~mm}\end{array}$ & No oscillations & No oscillations & No oscillations \\
\hline
\end{tabular}


Table 3. Experimental validation of location of $80 \mathrm{~K}$ intercept from literature [1]: tube length is 5 meter

\begin{tabular}{|c|c|c|c|c|}
\hline & Tube size & $\begin{array}{l}\text { Location of } 80 \mathrm{~K} \\
\text { intercept }\end{array}$ & $\begin{array}{l}\text { Thermo-acoustic } \\
\text { oscillation } \\
\text { occurrence, } \\
\text { experimental data } \\
\text { from Reference } 1\end{array}$ & $\begin{array}{l}\text { Predicted thermo- } \\
\text { acoustic oscillation } \\
\text { occurrence, data } \\
\text { from the present } \\
\text { analysis Figure } 10\end{array}$ \\
\hline & & No $80 \mathrm{~K}$ intercept & Oscillations & Oscillations \\
\hline & & $\begin{array}{l}80 \mathrm{~K} \text { intercept placed } \\
\text { at hot end }(\sim 300 \mathrm{~K}) \text {, } \\
\text { now boundary } \\
\text { conditions became } \\
4.5 \mathrm{~K}-80 \mathrm{~K} \text { and } \mathrm{L}= \\
5 \mathrm{~m}\end{array}$ & Oscillations & Oscillations \\
\hline & $\begin{array}{l}\text { OD } 6.35 \mathrm{~mm} \\
\text { ID } 4.57 \mathrm{~mm}\end{array}$ & $\begin{array}{l}80 \mathrm{~K} \text { intercept placed } \\
\text { at } 3 \mathrm{~m} \text { away from } \\
\text { cold end, now } \\
\text { boundary conditions } \\
\text { became } 4.5 \mathrm{~K}-80 \mathrm{~K} \\
\text { and } \mathrm{L}=3 \mathrm{~m}\end{array}$ & Oscillations & Oscillations \\
\hline & & $\begin{array}{l}80 \mathrm{~K} \text { intercept placed } \\
\text { at } 0.6 \mathrm{~m} \text { away from } \\
\text { cold end, now } \\
\text { boundary conditions } \\
\text { became } 4.5 \mathrm{~K}-80 \mathrm{~K} \\
\text { and } \mathrm{L}=0.6 \mathrm{~m}\end{array}$ & No oscillations & No oscillations \\
\hline & & No $80 \mathrm{~K}$ intercept & Oscillations & Oscillations \\
\hline & & $\begin{array}{l}80 \mathrm{~K} \text { intercept placed } \\
\text { at hot end }(\sim 300 \mathrm{~K}) \text {, } \\
\text { now boundary } \\
\text { conditions became } \\
4.5 \mathrm{~K}-80 \mathrm{~K} \text { and } \mathrm{L}= \\
5 \mathrm{~m}\end{array}$ & No oscillations & No oscillations \\
\hline & $\begin{array}{l}12.70 \mathrm{~mm} \\
10.92 \mathrm{~mm}\end{array}$ & $\begin{array}{l}80 \mathrm{~K} \text { intercept placed } \\
\text { at } 2 \mathrm{~m} \text { away from } \\
\text { cold end, now } \\
\text { boundary conditions } \\
\text { became } 4.5 \mathrm{~K}-80 \mathrm{~K} \\
\text { and } \mathrm{L}=2 \mathrm{~m}\end{array}$ & No oscillations & No oscillations \\
\hline & & $\begin{array}{l}80 \mathrm{~K} \text { intercept placed } \\
\text { at } 0.6 \mathrm{~m} \text { away from } \\
\text { cold end, now } \\
\text { boundary conditions } \\
\text { became } 4.5 \mathrm{~K}-80 \mathrm{~K} \\
\text { and } \mathrm{L}=0.6 \mathrm{~m}\end{array}$ & No oscillations & No oscillations \\
\hline
\end{tabular}




\section{Demonstration of application of present method}

For a helium cryostat design, the expected liquid helium filling temperature is $4.5 \mathrm{~K}$. Tubing needs to be design for this cryostat of which one end is at $4.5 \mathrm{~K}$ and other end is at room temperature $(300 \mathrm{~K})$. The tubing diameter of an appropriate length shall be determined with and without an $80 \mathrm{~K}$ intercept so that there are no oscillations present in the system.

Table 4 shows the required properties of oscillating helium gas at the cold end of tube, $\mathrm{T}_{\mathrm{L}}=4.5 \mathrm{~K}$.

Table 4. Sound speed, $a_{c}$, and kinematic viscosity of helium, $v_{c}$ at $\mathrm{T}_{\mathrm{L}}$

\begin{tabular}{|c|c|c|}
\hline & $a_{c}(\mathrm{~m} / \mathrm{s})$ & $\vartheta_{c}\left(\mathrm{~m}^{2} / \mathrm{s}\right)$ \\
\hline $\begin{array}{c}\text { Helium properties at } \mathrm{T}_{\mathrm{L}}= \\
4.5 \mathrm{~K} \text { and pressure, } \mathrm{p}= \\
1.3 \times 10^{5} \mathrm{~Pa}\end{array}$ & 100.4 & $6.22 \times 10^{-8}$ \\
\hline
\end{tabular}

5.1. Tube sizing of $2 \mathrm{~m}$ length without $80 \mathrm{~K}$ intercept

Eq. 7 has to be used to determine the minimum inner tube diameter. The other parameters which are required in Eq. 7 are:

$\mathrm{D}=1.19$ [2], $\alpha=300 / 4.5=66.67, \beta=0.647$ [2], $l=1 \mathrm{~m}$ for $\xi=1$ and $\lambda_{c}=1.0$

$d_{o, \text { critical }}=\frac{4 D \alpha^{1+\beta}}{\left(1+\xi^{-1}+\lambda_{c}^{2} \xi\right)}\left[\frac{l v_{c}}{a_{c}}\right]^{\frac{1}{2}}=\frac{4 X 1.19 X 66.67^{1.647}}{\left(1+1^{-1}+1^{2} X 1\right)} \sqrt{\frac{1 X 6.22 X 10^{-8}}{100.4}}$

The critical tube inner diameter $d_{o, \text { eritical }}=0.03986$ meter $=39.86 \mathrm{~mm}$. Figure 7 could also be directly used for determining the appropriate tubing sizing for oscillation-free design. 


\section{2. $\quad$ Tube sizing of $4 \mathrm{~m}$ length with an appropriate location of $80 \mathrm{~K}$ intercept}

A tube size of $6.35 \mathrm{~mm}$ OD, thickness $0.89 \mathrm{~mm}$ and length of $4 \mathrm{~m}$ has been selected for cryostat design of which one end is exposed to $4.5 \mathrm{~K}$ and other end is at room temperature, $300 \mathrm{~K}$. An $80 \mathrm{~K}$ intercept location shall be selected for oscillation-free design.

First Eq. 2 has to be used to determine the stability limit, $Y_{c}$, for temperature boundaries of $4.5 \mathrm{~K}-80 \mathrm{~K}$

$$
\begin{aligned}
Y_{c} & =\frac{2 D \alpha^{1+\beta}}{\left(1+\xi^{-1}+\lambda_{c}^{2} \xi\right)}=\frac{2 X 1.19 X 17.77^{1.647}}{\left(1+1^{-1}+1^{2} X 1\right)} \\
Y_{c} & =90.86
\end{aligned}
$$

Eq. 5 is subsequently applied to determine the stability limit $Y_{c}$. The stability limit calculated from Eq. 5 should be more than the above calculated value to make the design oscillation-free.

To calculate $Y_{c}$ from Eq. 5, let us choose the location of $80 \mathrm{~K}$ intercept $4 \mathrm{~m}$ away from cold end (i.e. at hot end) and therefore $l=2 m$ for $\xi=1$ and $d_{0}=6.35-2 \times 0.89=$ $4.57 \mathrm{~mm}$

$$
Y_{c}=\frac{d_{0}}{2}\left[\frac{a_{C}}{l v_{c}}\right]^{\frac{1}{2}}=\frac{4.57 \times 10^{-3}}{2} \sqrt{\frac{100.4}{2 \times 6.22 \times 10^{-8}}}=64.91
$$

The value of $Y_{c}$ is less than the above calculated value and therefore the location of the $80 \mathrm{~K}$ intercept will not be effective to make the design oscillation-free.

Now let us choose the another location of $80 \mathrm{~K}$ intercept $2 \mathrm{~m}$ away from cold end and therefore $l=1 \mathrm{~m}$ for $\xi=1$ and $\mathrm{d}_{\mathrm{o}}=6.35-2 \times 0.89=4.57 \mathrm{~mm}$

$$
Y_{c}=\frac{a_{o}}{2}\left[\frac{a_{c}}{l v_{c}}\right]^{\frac{1}{2}}=\frac{4.57 \times 10^{-3}}{2} \sqrt{\frac{100.4}{1 \times 6.22 \times 10^{-8}}}=91.81
$$


The value of $Y_{C}$ is more than the above calculated value and therefore the location of 80 $\mathrm{K}$ intercept will make the design oscillation free.

\section{Conclusions}

This analysis presents a simple method to size helium tubes that will be free of thermoacoustic oscillations. The presented figures can serve as a reference for determining the oscillating and non-oscillating zones for different tube length-diameter combinations. Design guidelines can also be obtained for sizing oscillation-free helium tubes when inserts are used. The analysis provides useful information for an appropriate location of an $80 \mathrm{~K}$ intercept to avoid thermo-acoustic oscillations and is verified against the available experimental results. This analysis is based on the lower stability curve of Rott's analysis.

\section{Acknowledgments:}

The Fermi National Accelerator Laboratory is operated by Fermi Research Alliance, LLC under Contract No. DE $\square$ AC02 $\square 07 \mathrm{CH} 11359$ with the United States Department of Energy. 


\section{References:}

1. Fuerst JD. An Investigation of Thermally Driven Acoustical Oscillations in Helium System. Low Temperature Engineering and Cryogenic Conference and Exhibition, July 17-19, 1990. Source: http://lss.fnal.gov/archive/testtm/1000/fermilab-tm-1676.pdf.

2. Rott N.Thermally Driven Acoustic Oscillations. Part II: Stability Limit for Helium. Journal of Applied mathematics and Physics, Vol.24, 1973; 54-72.

3. Yazaki T. Experimental Oservation of Thermoacoustic Turbulence and Universal Properties at the Quasiperiodic Transition to Chaos. Physical Review E, Volume 48, September 1993; 1806-1818.

4. Gu Youfan, Timmerhaus KD. Experimental Verification of Stability Characteristics for Thermal Acoustic Oscillations in a Liquid Helium System. Advanced in Cryogenic Engineering, Vol. 39, 1994;1733-1740. 
Table 1. Experimental verification of present helium piping design from the experimental results available in open literature [1, 4]: hot end at $300 \mathrm{~K}$, cold end at $4.5 \mathrm{~K}$, tube length: 1 meter

\begin{tabular}{|c|c|c|c|}
\hline Tube/pipe Sizes & $\begin{array}{l}\text { Thermo-acoustic } \\
\text { oscillation } \\
\text { occurrence, } \\
\text { experimental data } \\
\text { from Reference } 1\end{array}$ & $\begin{array}{l}\text { Thermo-acoustic } \\
\text { oscillation } \\
\text { occurrence, } \\
\text { experimental data } \\
\text { from Reference } 4\end{array}$ & $\begin{array}{l}\text { Predicted } \\
\text { thermo-acoustic } \\
\text { oscillation } \\
\text { occurrence, data } \\
\text { from the present } \\
\text { analysis Figure } 7\end{array}$ \\
\hline $\begin{array}{ll}\text { OD } & 3.18 \mathrm{~mm} \\
\text { ID } & 1.40 \mathrm{~mm}\end{array}$ & Oscillations & Oscillations & Oscillations \\
\hline $\begin{array}{ll}\text { OD } & 6.35 \mathrm{~mm} \\
\text { ID } & 4.57 \mathrm{~mm}\end{array}$ & Oscillations & Oscillations & Oscillations \\
\hline $\begin{array}{ll}\text { OD } & 12.70 \mathrm{~mm} \\
\text { ID } & 10.92 \mathrm{~mm}\end{array}$ & Oscillations & Oscillations & Oscillations \\
\hline $\begin{array}{r}42.20 \mathrm{~mm} \\
38.90 \mathrm{~mm}\end{array}$ & No oscillations & No oscillations & $\begin{array}{c}\text { No oscillations } \\
\text { Minimum critical } \\
\text { diameter is } 28.2 \mathrm{~mm}\end{array}$ \\
\hline
\end{tabular}


Table 2. Experimental verification of present helium piping design from the experimental results available in open literature [1,4]: hot end at $80 \mathrm{~K}$, cold end at $4.5 \mathrm{~K}$, tube length: 1 meter

\begin{tabular}{|c|c|c|c|}
\hline Tube Sizes & $\begin{array}{l}\text { Thermo-acoustic } \\
\text { oscillation } \\
\text { occurrence, } \\
\text { experimental data } \\
\text { from Reference } 1\end{array}$ & $\begin{array}{l}\text { Thermo-acoustic } \\
\text { oscillation } \\
\text { occurrence, } \\
\text { experimental data } \\
\text { from Reference } 4\end{array}$ & $\begin{array}{l}\text { Predicted } \\
\text { thermo-acoustic } \\
\text { oscillation } \\
\text { occurrence, data } \\
\text { from the present } \\
\text { analysis Figure } 7\end{array}$ \\
\hline $\begin{array}{ll}\text { OD } & 3.18 \mathrm{~mm} \\
\text { ID } & 1.40 \mathrm{~mm}\end{array}$ & Oscillations & Oscillations & Oscillations \\
\hline $\begin{array}{ll}\text { OD } & 6.35 \mathrm{~mm} \\
\text { ID } & 4.57 \mathrm{~mm}\end{array}$ & No oscillations & No oscillations & No oscillations \\
\hline $\begin{array}{ll}\text { OD } & 12.70 \mathrm{~mm} \\
& \\
\text { ID } & 10.92 \mathrm{~mm}\end{array}$ & No oscillations & No oscillations & No oscillations \\
\hline
\end{tabular}


Table 3. Experimental validation of location of $80 \mathrm{~K}$ intercept from literature [1]: tube length is 5 meter

\begin{tabular}{|c|c|c|c|c|}
\hline \multicolumn{2}{|c|}{ Tube size } & $\begin{array}{l}\text { Location of } 80 \mathrm{~K} \\
\text { intercept }\end{array}$ & $\begin{array}{l}\text { Thermo-acoustic } \\
\text { oscillation } \\
\text { occurrence, } \\
\text { experimental data } \\
\text { from Reference } 1\end{array}$ & $\begin{array}{l}\text { Predicted } \\
\text { thermo-acoustic } \\
\text { oscillation } \\
\text { occurrence, data } \\
\text { from the present } \\
\text { analysis Figure } 10\end{array}$ \\
\hline \multirow{3}{*}{\multicolumn{2}{|c|}{ OD $6.35 \mathrm{~mm}$}} & No $80 \mathrm{~K}$ intercept & Oscillations & Oscillations \\
\hline & & $\begin{array}{l}80 \mathrm{~K} \text { intercept placed } \\
\text { at hot end }(\sim 300 \mathrm{~K}) \text {, } \\
\text { now boundary } \\
\text { conditions became } \\
4.5 \mathrm{~K}-80 \mathrm{~K} \text { and } \mathrm{L}=5 \\
\mathrm{~m}\end{array}$ & Oscillations & Oscillations \\
\hline & & $\begin{array}{l}80 \mathrm{~K} \text { intercept placed } \\
\text { at } 3 \mathrm{~m} \text { away from }\end{array}$ & & \\
\hline & $4.57 \mathrm{~mm}$ & $\begin{array}{l}\text { cold end, now } \\
\text { boundary conditions } \\
\text { became } 4.5 \mathrm{~K}-80 \mathrm{~K} \\
\text { and } \mathrm{L}=3 \mathrm{~m}\end{array}$ & Oscillations & Oscillations \\
\hline & & $\begin{array}{l}80 \mathrm{~K} \text { intercept placed } \\
\text { at } 0.6 \mathrm{~m} \text { away from } \\
\text { cold end, now } \\
\text { boundary conditions } \\
\text { became } 4.5 \mathrm{~K}-80 \mathrm{~K} \\
\text { and } \mathrm{L}=0.6 \mathrm{~m}\end{array}$ & No oscillations & No oscillations \\
\hline \multirow[b]{2}{*}{$\begin{array}{l}\text { OD } \\
\text { ID }\end{array}$} & & No $80 \mathrm{~K}$ intercept & Oscillations & Oscillations \\
\hline & $\begin{array}{l}12.70 \mathrm{~mm} \\
10.92 \mathrm{~mm}\end{array}$ & $\begin{array}{l}80 \mathrm{~K} \text { intercept placed } \\
\text { at hot end }(\sim 300 \mathrm{~K}) \text {, } \\
\text { now boundary } \\
\text { conditions became } \\
4.5 \mathrm{~K}-80 \mathrm{~K} \text { and } \mathrm{L}=5 \\
\mathrm{~m}\end{array}$ & No oscillations & No oscillations \\
\hline
\end{tabular}




\begin{tabular}{|l|l|l|l|}
\hline & $\begin{array}{l}80 \mathrm{~K} \text { intercept placed } \\
\text { at } 2 \mathrm{~m} \text { away from } \\
\text { cold end, now } \\
\text { boundary conditions } \\
\text { became } 4.5 \mathrm{~K}-80 \mathrm{~K} \\
\text { and } \mathrm{L}=2 \mathrm{~m}\end{array}$ & No oscillations & No oscillations \\
\cline { 2 - 4 } & $\begin{array}{l}80 \mathrm{~K} \text { intercept placed } \\
\text { at } 0.6 \mathrm{~m} \text { away from } \\
\text { cold end, now } \\
\text { boundary conditions } \\
\text { became } 4.5 \mathrm{~K}-80 \mathrm{~K} \\
\text { and } \mathrm{L}=0.6 \mathrm{~m}\end{array}$ & No oscillations & No oscillations \\
\hline
\end{tabular}


Table 4. Sound speed, $a_{c}$, and kinematic viscosity of helium, , at $T_{\mathrm{L}}$

\begin{tabular}{|c|c|c|}
\hline & $a_{c}(\mathrm{~m} / \mathrm{s})$ & $\left(\mathrm{m}^{2} / \mathrm{s}\right)$ \\
\hline $\begin{array}{c}\text { Helium properties at } \mathrm{T}_{\mathrm{L}}=4.5 \\
\mathrm{~K} \text { and pressure, } \mathrm{p}=1.3 \mathrm{X} \\
10^{5} \mathrm{~Pa}\end{array}$ & 100.4 & $6.22 \times 10^{-8}$ \\
\hline
\end{tabular}

